13th. Patient dressed herself and remained out of bed nearly all day; eats heartily and is gaining strength rapidly.

18th. Patient going about the honse; has a good appetite ; sleeps well and declares that she never felt better in her life.

April 19th, 1868. I visited Mrs. H. this morning; her health has been very good since her recovery from the operation. She menstruates regularly and there has been no tendency to hernia, where the incision was made.

Large Salivary Calculus Removed from Wharton's Duct of Right Submaxillary Gland. By Jonn L. Firestone, M. D., of Salem, Ohio.

A farmer, æt. fifty, called on me with a tumour in the floor of the mouth, under the right side of the tongne, which had been noticed a "good while," as it interfered somewhat with mastication, though not with deglutition.

On examination a hard tumour was felt in the place designated, apparently about the size of a hulled walnut, and on the floor of the mouth Wharton's duct was seen unusually open. A probe was easily introduced, and immediately below the surface struck a hard, rongh calculus. Introduced a narrow-bladed bistonry and opened the sac parallel with the tongue, and, with the scoop end of a director, I removed a calculns 14 lines long, 8 broad, and 6 decp, and $1 \frac{1}{2}$ drachm in weight. It was yellowishwhite; oval, with flattened sides; and was composed of "phosphate and carbonate of lime, held together by animal matter."

This salivary calculus is probably of unnsual size. Rokitansky says, referring to these formations, that they vary in size "from a millet-seed or a pea, to even that of a hazel-nut."

Amputation at the Hip-Joint. By B. RoHrer, Surg. 10th P. R. V. C. Frank G., a private in a Texan regiment, was wounded at the battle of Gettysburg. The wound was in the left thigh, cansed by a grape-shot, which entered two inches below the trochanter major, shattered the bone up into the neck, and lacerated the soft parts terribly between the place of entrance and the knee. He remained on the battle-field from the second until the fourth day of July, with very little attention until he was brought to the hospital of the Fifth Army Corps. After a consultation with a number of surgeons, and the conclusion being in favour of amputation at the hip, the patient was placed upon the table, and, when fully under the influence of chloroform, I performed the antero-posterior operation, assisted by Jos. A. Philips, Surgeon-General of Pennsylvania, and Henry Grimm, Surg. 12th Pa. Reserve Vol. Corps. Surg. Philips controlled the femoral artery, and not over three onuces of blood were lost. Death followed in thirty-six hours.

\title{
DOMESTIC SUMMARY.
}

Physiological Action of the Bromide of Potassium.-Onr contemporary, the Boston Med. and Surg. Joum. (Oct. 22, 1868), contains an interesting paper by Dr. H. P. BowDitce, on this subject, giving the results of recent observations, and of some experiments made at the Massachusetts Medical School during the past spring, by a class of students under the direction of Prof. E. H. Clarke and Dr. R. Amory. 
The author thinks that from these experiments and observations he may draw the following conclusions:-

"1. The bromide of potassium is rapidly absorbed.

" 2 . Though it appears quickly in the urine, it is, upon the whole, not rery rapidly eliminated.

"3. It is eliminated unchanged by the kidneys, the skin, and, perhaps, by the intestines.

"4. It is sometimes decomposed in the system and free bromine eliminated by the breath.

" 5 . While passing into the system it acts as a local irritant on the surfaces through which it passes.

" 6 . While in the system it acts as a vascular and nervous sedative.

"7. While passing out of the system its primary effect is to diminish all the secretions, except perhaps the urine, but secondarily hypersecretion may be induced."

Acupressure of Arteries.-Dr. Hutchinson presented to the New York Pathological Society the carotid artery of a dog, that had heen closed in its continuity by acupressure. The pressure was discontinned at the end of twenty-four hours, and the artery itself removed twenty-four days after the operation. A quarter of an inch above and below the constriction the vessel was obliterated and converted into a fibrous cord, as proved by microscopical examination by Dr. Stiles, of Brooklyn.

He remarked in that connection that during the last twelve months he had acupressed fifty arteries: one in a case of amputation at the knee-joint; two in amputation of the leg; two of forearm; one of the arm; one of the foot; and in several smaller operations. In all these cases the union was more rapid than when the ligature was applied, and there was never any secondary hemorrhage. The needles were removed from the radial and ulnar in twenty-two hours, from the popliteal in forty-eight hours, while in some smaller vessels thirteen hours sufficed.-Med. Record, Dec. 1, 1868.

Treatment of Organic Infantile Paralysis by the Continuous Galvanic Current. - Dr. W M. A. HAmmond states (Quarterly Journ. Psychological Med., $\left.J_{11} y, 1868\right)$ that some time since he gave his views relative to the pathology and treatment of a very persistent form of infantile paralysis, and that he is now in a position to speak more anthoritatively on the subject. He then insisted upon the employment of the direct galvanic current as indispensable in those instances where the muscles would not contract to the stimulus of the induced current, and referred to sereral cases in which its efficacy had been clearly established. Since that time he has had many opportunities of testing the advantages of this therapeutic agent: and has moreover been using a battery far more efficacious and convenient than any that has come under his notice. This battery is the one invented and manufactured by Dr. Emil Stöhrer, of Iresden. "The advantages of this battery," he says, " are inestimable. When not in use there is no destruction of zinc, or deterioration of acids. The current is regular and constant, and with a daily use of from four to six hours, for three nionths, I have not had to renew the acids, cleanse the carbon cylinders, nor amalgamate those of zinc. The whole arrangement is fully described in Ziemper's Electricität in der Medicin. Zweite autlage. Berlin, 1864, p.81; to which work the rcader is referred for a fuller account of this admilable apparatus."

Dr. H. says: "It would be tedious to describe at length all the cases of infantile paralysis which I have treated with the direct galvanic current. If a contraction can be induced by it, recovery is merely a mattcr of time, but if no action of the paralyzed muscles can be brought about, the prognosis must be unfavoulable. But even here there is hope, for in a recent case sent to me by my friend, Professor W. H. Van Buren, M. D., where, after the application of the current from Stöhrer's machine, no contraction could be caused in a puralyzed tibialis anticus muscle, I succeeded a few days afterward in producing very decided action by the same means.

"In only three cases which have come under my notice was the disease so 